\title{
Estimating Maternal Mortality Level in Rural Northern Nigeria by the Sisterhood Method
}

\author{
Henry V. Doctor, ${ }^{1,2}$ Sally E. Findley, ${ }^{1}$ and Godwin Y. Afenyadu ${ }^{2}$ \\ ${ }^{1}$ Department of Population and Family Health, Mailman School of Public Health, Columbia University, 60 Haven Avenue, \\ Suite B2, New York, NY 10032, USA \\ ${ }^{2}$ Partnership for Reviving Routine Immunization in Northern Nigeria (PRRINN); Maternal, Newborn and \\ Child Health (MNCH) Program, Nassarawa GRA, Kano State, Nigeria \\ Correspondence should be addressed to Henry V. Doctor, hvd2105@columbia.edu
}

Received 23 March 2012; Revised 26 July 2012; Accepted 10 August 2012

Academic Editor: Kristin L. Dunkle

Copyright ( $) 2012$ Henry V. Doctor et al. This is an open access article distributed under the Creative Commons Attribution License, which permits unrestricted use, distribution, and reproduction in any medium, provided the original work is properly cited.

\begin{abstract}
Maternal mortality is one of the major challenges to health systems in sub Saharan Africa. This paper estimates the lifetime risk of maternal death and maternal mortality ratio (MMR) in four states of Northern Nigeria. Data from a household survey conducted in 2011 were utilized by applying the "sisterhood method" for estimating maternal mortality. Female respondents (15-49 years) were interviewed thereby creating a retrospective cohort of their sisters who reached the reproductive age of 15 years. A total of 3,080 respondents reported 7,731 maternal sisters of which 593 were reported dead and 298 of those dead were maternal-related deaths. This corresponded to a lifetime risk of maternal death of $9 \%$ (referring to a period about 10.5 years prior to the survey) and an MMR of 1,271 maternal deaths per 100,000 live births; 95\% CI was 1,152-1,445 maternal deaths per 100,000 live births. The study calls for improvement of the health system focusing on strategies that will accelerate reduction in MMR such as availability of skilled birth attendants, access to emergency obstetrics care, promotion of facility delivery, availability of antenatal care, and family planning. An accelerated reduction in MMR in the region will contribute towards the attainment of the Millennium Development Goal of maternal mortality reduction in Nigeria.
\end{abstract}

\section{Introduction}

Maternal mortality is one of the major challenges to health systems in the world and sub Saharan Africa in particular [1]. In order to encourage the international community to address this challenge, maternal mortality reduction was included as one of the Millennium Development Goals, MDG 5. The target of MDG 5 is to reduce maternal mortality ratio (MMR) by 75\%, from 1990 to 2015 [2].

Although several studies $[3,4]$ have highlighted the slow progress in reducing maternal mortality, global reduction in maternal deaths with variations across countries has been reported elsewhere [1]. Global maternal deaths reduced by $35 \%$ from 526,300 in 1980 to 342,900 in 2010. In Nigeria, the MMR in 2008 was reported to be 608 deaths per 100,000 live births (95\% confidence interval (CI): 372-946). This was an increase from an MMR of 473 (95\% CI: 306-703) in 1990
[1]. Despite challenges of measuring maternal mortality, the need for monitoring of maternal mortality is a priority for many countries including Nigeria. Estimates of maternal mortality are indispensable for planning and monitoring the outcomes or impact of interventions. Recently, Nigeria expressed reservations about accuracy and methods used to obtain figures quoted and the bases for such estimates [5].

A number of countries have strengthened their efforts to improve the quality of information about maternal mortality such as incorporation of sibling history modules in largescale household surveys, whether recent deaths in censuses were related to pregnancies, and the use of record linkage or confidential inquiry to identify under-registration of (maternal) deaths in vital registration systems [6]. Despite these efforts, vital registration is virtually nonexistent in Nigeria.

Existing efforts to study maternal mortality in sub Saharan Africa are often met with key challenges: large sample 
sizes are required for these rare events, majority of maternal deaths occur at home, and follow-up studies take time. The "sisterhood method" for estimating MMR is an ideal method in such settings since it requires fewer respondents than vital registration and cohort studies. Data collection procedures for this method are retrospective (a period of about 1012 years before the survey), simple, quick, and based on information about maternal deaths among sisters of the respondents [7]. Nevertheless, this method is not used to measure progress towards safe motherhood in the short term nor evaluate program impact [8]. Another disadvantage is that it provides estimates of maternal mortality that should be seen as orders of magnitude rather than precise ratios since they can have wide CIs. The method does not provide a current estimate for the year of the survey. In general, the estimates from this method are fairly precise and the level of accuracy may be low due to the retrospective nature of the data and lack of verification of the information provided.

In this paper, we estimate the lifetime risk of maternal death and the associated MMR. This method has been used and validated elsewhere $[9,10]$. Maternal and child health data were collected from women of reproductive age (1549 years) as part of household survey conducted by the Partnership for Reviving Routine Immunization in Northern Nigeria; Maternal Newborn and Child Health (PRRINN$\mathrm{MNCH}$ ) Program (hereafter "the program") in July-August 2011 in four northern states (Jigawa, Katsina, Yobe, and Zamfara) to track the progress on baseline or preintervention levels (based on the 2009 survey) of some program processes, outcome, and impact indicators. The 2009 household survey did not include sisterhood questions.

What is the level of maternal mortality in the study area? In order to answer this question, we analyze household survey data collected by the program in 2011 by using the sisterhood method. The estimated level of maternal mortality would then be used for advocacy by drawing the attention of policymakers and other stakeholders to the problem and hope that they will deploy interventions to address the problem.

\section{Methods}

2.1. Setting. According to the 2006 population census, Jigawa, Katsina, Yobe, and Zamfara States had an estimated population of $4.3,5.8,2.3$, and 3.3 million people, respectively. These four states were selected for the program activities because they have generally poor maternal and child health indicators. For example, MMRs are over 1,000 deaths per 100,000 live births (significantly higher than the national average) [11]. Antenatal care services are available in selected health facilities in these states and according to the Nigerian Demographic and Health Survey of 2008, in the northern region, $59.1 \%$ of pregnant women in the five years preceding the survey had no antenatal care, and among those receiving antenatal care, only $37 \%$ received such services from a skilled provider. About nine out of 10 women $(88.4 \%)$ in this region delivered at home, with infant and child mortality rates well above the national average of 75 deaths per 1,000 live births and 88 deaths per 1,000 children, respectively [12].

The program was established in 2007-2008 with cofunding from the Department for International Development (UK) and the Norwegian Government. In each state, the program generally focuses on increasing demand for $\mathrm{MNCH}$ services (through community mobilization and awareness creation, among others) and strengthening the supply system (through, improving health facility staffing, drug supplies, and equipment, emergency transport scheme, among others) with an ultimate goal of ensuring that all women know maternal danger signs, deliver with skilled birth attendants, and have access to emergency care. This integrated approach complements state governments efforts towards achieving MDGs for child and maternal mortality reduction.

2.2. Data Collection. As part of the program's monitoring and evaluation activities, a household survey was conducted in 2011 to generate information on selected performance indicators. This follows a similar survey conducted in 2009. A sample of 770 women of reproductive age (15-49 years) per state was selected and designed to represent intervention and control communities.

Sisterhood questions were included in this survey to help estimate MMR and to provide evidence and validate the speculation that MMR in Northern Nigeria is more than a 1,000 deaths per 100,000 live births. The specific questions were as follows: (1) how many sisters have you ever had who reached reproductive age ( 15 years)? (2) how many of these sisters are alive? (3) how many of these sisters are dead? (4) how many of these sisters died during pregnancy, labor or within 42 days after the delivery? Interviewers checked that the sum of questions two and three was equal to the total in question one. Trained interviewers visited the selected women at home and administered a questionnaire, which included translation of key concepts and terms into the local languages, Hausa or Kanuri. The inclusion of the sisterhood questions in the survey was therefore not for the purposes of tracking trends or measuring the impact of the program interventions.

The fieldwork for the survey took place between July and August 2011. Respondents were interviewed using a structured questionnaire on a series of maternal and child health related questions. The inclusion criteria for reported sisters were that they were born to the same mother as the respondent and had reached reproductive age (15 years). Migration of women in the study area is insignificant, an important factor since migration can compromise the completeness of the information gathered by failing to report dead sisters who had migrated.

2.3. Analysis. The data on sibling histories from the sisterhood questions were disaggregated into 5-year age groups. For each age group, the number of sisters exposed to the risk of maternal death and the duration of their exposure (i.e., the number of reproductive years) was calculated by multiplying the number of sisters by an age-specific adjustment. The lifetime risk (LTR) of maternal death was 
TABLE 1: Responses of 3,080 respondents about their sister's vital status and LTR of maternal death, selected states, Northern Nigeria, 2011.

\begin{tabular}{|c|c|c|c|c|c|c|c|}
\hline Column 1 & Column 2 & Column 3 & Column 4 & Column 5 & Column 6 & Column 7 & Column 8 \\
\hline $\begin{array}{l}\text { Age group } \\
\text { of respondent }\end{array}$ & $\begin{array}{c}\text { Number of } \\
\text { respondents } \\
(\%)\end{array}$ & $\begin{array}{l}\text { Number of } \\
\text { sisters }\end{array}$ & $\begin{array}{c}\text { Number of } \\
\text { sisters } \\
\text { who died (\%) }\end{array}$ & $\begin{array}{c}\text { Number of } \\
\text { maternal } \\
\text { deaths (\%) }\end{array}$ & $\begin{array}{l}\text { Adjustment } \\
\text { factor }\end{array}$ & $\begin{array}{c}\text { Sisters exposed } \\
(\text { Col. } 3 * \text { Col. } \\
6)\end{array}$ & $\begin{array}{l}\text { Lifetime risk } \\
\text { (Col.5/Col.7) }\end{array}$ \\
\hline $15-19$ & $217(7.0)$ & 375 & $23(3.9)$ & $7(2.3)$ & 0.107 & 40 & 0.17 \\
\hline $20-24$ & $713(23.1)$ & 1607 & $120(20.2)$ & $50(16.8)$ & 0.206 & 331 & 0.15 \\
\hline $25-29$ & 799 (25.9) & 2099 & $169(28.5)$ & $75(25.2)$ & 0.343 & 720 & 0.10 \\
\hline $30-34$ & $724(23.5)$ & 1863 & $124(20.9)$ & $76(25.5)$ & 0.503 & 937 & 0.08 \\
\hline $35-39$ & $363(11.8)$ & 951 & $71(12.0)$ & $37(12.4)$ & 0.664 & 631 & 0.06 \\
\hline $40-44$ & $211(6.9)$ & 696 & $77(13.0)$ & $45(15.1)$ & 0.802 & 558 & 0.08 \\
\hline $45-49$ & $53(1.7)$ & 140 & $9(1.5)$ & $8(2.7)$ & 0.900 & 126 & 0.06 \\
\hline Total & $3,080(100.0)$ & 7,731 & $593(100.0)$ & $298(100.0)$ & & 3,344 & 0.09 \\
\hline
\end{tabular}

$\mathrm{MMR}=1,271$ maternal deaths per 100,000 live births; $95 \% \mathrm{CI}$ is $1,152-1,445$.

calculated using the total number of maternal deaths divided by the estimated total number of sisters exposed. An average estimate of total fertility rate (TFR) was obtained from the 2008 Demographic and Health Survey [12]. In 2008, the average TFR for all the states was 7.3. The formula to calculate and approximate MMR from the LTR [7] was: MMR $=1-[(1-\mathrm{LTR}) *(1 / \mathrm{TFR})]$. Ninety-five percent CIs for the MMR were calculated based on [13].

\section{Results}

Studies using the sisterhood technique provide reasonable estimates if 3,000 sisters or more are studied [7]. As a result, our analyses aggregated all the women from all the states. A total of 3,080 respondents reported 7,731 maternal sisters of which 593 were reported dead and 298 of those dead were maternal-related deaths. Table 1 shows the sister's vital status, by 5 -year age groups and LTR of maternal death for all the states, and estimated LTR for the entire cohort. The total LTR of maternal death was $9 \%$ (or about 1 in 11) and using 7.3 as the TFR for all the states, the average MMR in the study area was 1,271 maternal deaths per 100,000 live births, $95 \%$ CI was 1,152-1,445 maternal deaths per 100,000 live births. The LTR refers to a period about 10.5 years prior to the survey.

The results in Table 1 also show a common trend of high maternal mortality in the age groups 20-24, 25-29, and 3034 in which at least $16 \%$ of the death reported by surviving sisters was a maternal death. The LTR among the age groups is relatively stable and declining at least for the first four age groups (Table 1).

\section{Discussion}

Much has been speculated about the level of maternal mortality in Northern Nigeria, with MMR speculated to be in excess of 1,000 maternal deaths per 100,000 live births [11]. Our study confirmed this speculation by documenting an MMR of 1,271 maternal deaths per 100,000 live births from the four states. The MMR estimate based on respondents aged 30 years and below was very high at 1,751 maternal deaths per 100,000 live births underscoring the fact that the maternal mortality situation in the rural areas of Northern Nigeria is one of the worst worldwide, and largely due to poor health systems, low utilization of skilled antenatal care, and preference for home deliveries [14]. The MMR reported in this study is also much higher than the latest national estimate of 608 maternal deaths per 100,000 live births [1].

This study provides very rough estimates on maternal mortality in selected states of northern Nigeria and complements some of the previous MMR figures which have generally been speculative with reference to MMR being "in excess of 1,000 deaths per 100,000 live births" [11]. The results reported here demonstrate the grim situation experienced by rural women of northern Nigeria who are challenged with poor health infrastructure, poorly equipped health facilities, and attitudes that we think are not conducive to attaining good maternal and child health. Programs aimed at improving the infrastructure and access to health services in rural areas will probably have a great impact in improving maternal health. Innovations such as those pioneered by the program on emergency transport scheme for emergency obstetric cases as well as improving access to quality emergency obstetric care (EOC) services especially in rural areas will help to stem the high level of maternal mortality. Creating demand through community sensitization on the benefits of antenatal care, availability of emergency transport system, and EOC services will increase utilization of maternal and child health services.

The high burden of maternal death in the youngest age groups compared with the oldest age groups may be associated with low age at marriage, a typical occurrence in rural Northern Nigerian settings. Although our study could not ascertain the prevalence of low age at marriage, since age misreporting is one of the challenges experienced in the study areas and the absence of indicators to capture the age at death of the deceased, early marriages in this part have been documented elsewhere $[15,16]$. This underscores the fact that interventions that delay pregnancy could be effective in minimizing LTR of maternal death.

Out-migration, which may have an effect on MMR in settings with substantial migration rate, is not likely to affect 
the MMR estimate reported here since observed migration patterns in the area are mostly due to marriages. Similarly, abortion-related deaths — which may have been classified as deaths due to causes unrelated to pregnancy or childbirth and thus led to underestimate of the MMR - may likely have no impact in the study area as there are no or very minimal cases of out of wedlock pregnancies or births.

This study has three key limitations. First, the study comes from selected communities in the four states and the prevailing conditions are probably fairly similar to other parts of the states. However, these results cannot be generalized to other rural areas due to disparities in health service delivery and accessibility limits. Secondly, we had no information on the residence of the sisters in the cohort and proxied it with the respondent's community. Third, despite the estimates of lifetime risk referring to a period of about 10.5 years prior to the survey and the inability of the estimation method to provide the more recent MMR for the study area, our results call for intensification of health service delivery that takes into consideration the geographical characteristics of the area such as terrain.

\section{Conclusion}

Our study from rural Northern Nigeria has shown a high level of maternal mortality with an estimated MMR of 1,271 (95\% CI 1,152-1,445) maternal deaths per 100,000 live births. Despite the fact that these estimates refer to a period of about 10.5 years prior to the survey and the inability of the study to provide more recent estimates of MMR, we hope that the government's as well as other local and international partners' focus on EOC services will hopefully improve the lives of mothers. Further improvement of the health system with emphasis on interventions that will accelerate reduction of MMR such as availability of skilled birth attendants, promotion of facility delivery, availability of antenatal care in all facilities, antenatal care attendance, implementation of the emergency transport scheme in hard-to-reach rural areas, and family planning will help in accelerating attainment of MDG 5.

\section{Conflict of Interests}

The authors declare no conflict of interest.

\section{Acknowledgments}

PRRINN-MNCH Program is funded and supported by the Department for International Development (UK) and the Norwegian Government. The authors also acknowledge the support received from the program management and staff, Dr. Solomon Mengiste (Health Information Management Advisor), state operations research coordinators, Mr. Abdulazeez Jumare (Data Manager), the state operations research teams, field supervisors, fieldworkers, data entry clerks, and community members for their cooperation and continued support during the data collection. The views expressed in this paper are those of the authors and do not represent the policy of the program nor that of the donors. The authors are also grateful for very useful comments from an anonymous referee. Any remaining errors are theirs.

\section{References}

[1] M. C. Hogan, K. J. Foreman, M. Naghavi et al., "Maternal mortality for 181 countries, 1980-2008: a systematic analysis of progress towards Millennium Development Goal 5," The Lancet, vol. 375, no. 9726, pp. 1609-1623, 2010.

[2] United Nations General Assembly, United Nations Millennium Declaration, United Nations, New York, NY, USA, 2000, A/RES/55/2.

[3] K. Hill, K. Thomas, C. AbouZahr et al., "Estimates of maternal mortality worldwide between 1990 and 2005: an assessment of available data," The Lancet, vol. 370, no. 9595, pp. 1311-1319, 2007.

[4] United Nations, The Millennium Development Goals Report 2009, United Nations, New York, NY, USA, 2009.

[5] Nigeria Federal Ministry of Health, Concept Note on Health System Strengthening Initiative: Consensus Strategy for Mortality Estimation, Federal Ministry of Health, Abuja, Nigeria, 2011.

[6] N. Schuitemaker, J. van Roosmalen, G. Dekker, P. van Dongen, H. van Geijn, and J. B. Gravenhorst, "Underreporting of maternal mortality in the Netherlands," Obstetrics and Gynecology, vol. 90, no. 1, pp. 78-82, 1997.

[7] W. Graham, W. Brass, and R. W. Snow, "Estimating maternal mortality: the sisterhood method," Studies in Family Planning, vol. 20, no. 3, pp. 125-135, 1989.

[8] World Health Organization, The Sisterhood Method for Estimating Maternal Mortality: Guidance Notes for Potential Users, WHO and UNICEF, Geneva, 1997, WHO/RHT/97. 28, $\mathrm{UNICEF/EPP/97.} 1$.

[9] J. F. Etard, B. Kodio, and S. Traoré, "Assessment of maternal mortality and late maternal mortality among a cohort of pregnant women in Bamako, Mali," British Journal of Obstetrics and Gynaecology, vol. 106, no. 1, pp. 60-65, 1999.

[10] B. E. Olsen, S. G. Hinderaker, M. Kazaura et al., "Estimates of maternal mortality by the sisterhood method in rural northern Tanzania: a household sample and an antenatal clinic sample," British Journal of Obstetrics and Gynaecology, vol. 107, no. 10, pp. 1290-1297, 2000.

[11] Centre for Reproductive Rights and Women Advocates Research and Documentation Centre, Broken Promises: Human Rights, Accountability, and Maternal Death in Nigeria, Centre for Reproductive Rights and Women Advocates Research and Documentation Centre, New York, NY, USA, 2008.

[12] National Population Commission [Nigeria] and ICF Macro, Nigeria Demographic and Health Survey 2008, National Population Commission and ICF Macro, Abuja, Nigeria, 2009.

[13] J. A. Hanley, C. A. Hagen, and T. Shiferaw, "Confidence intervals and sample-size calculations for the sisterhood method of estimating maternal mortality," Studies in Family Planning, vol. 27, no. 4, pp. 220-227, 1996.

[14] H. V. Doctor, R. Bairagi, S. E. Findley, S. Helleringer, and D. Tukur, "Northern Nigeria Maternal, Newborn and Child Health Programme: selected analyses from population-based baseline survey," The Open Demography Journal, vol. 4, pp. 1121, 2011. 
[15] A. S. Erulkar and M. Bello, "The Experience of Married Adolescent Girls in Northern Nigeria, New York: Population Council," 2007, http://www.popcouncil.org/pdfs/Nigeria_MarriedAdol.pdf.

[16] National Population Commission [Nigeria], Nigeria Demographic and Health Survey, 1999, National Population Commission, Calverton, Md, USA, 2000. 


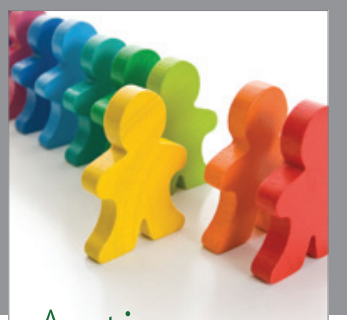

Autism

Research and Treatment
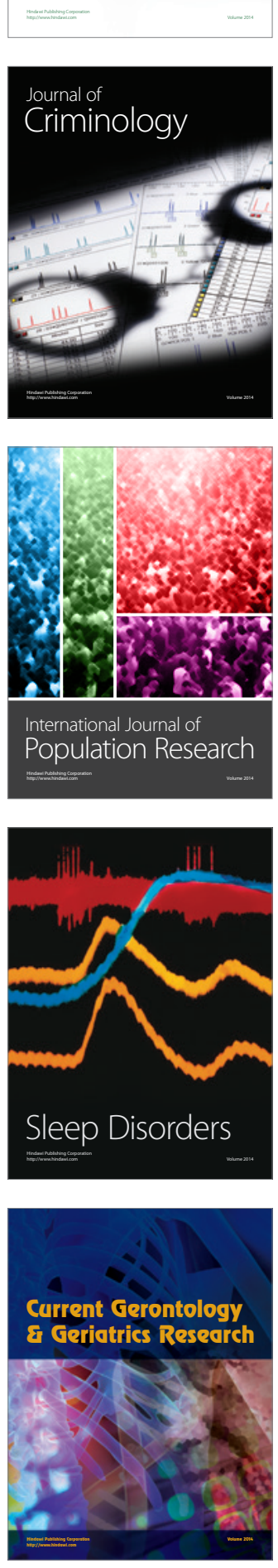
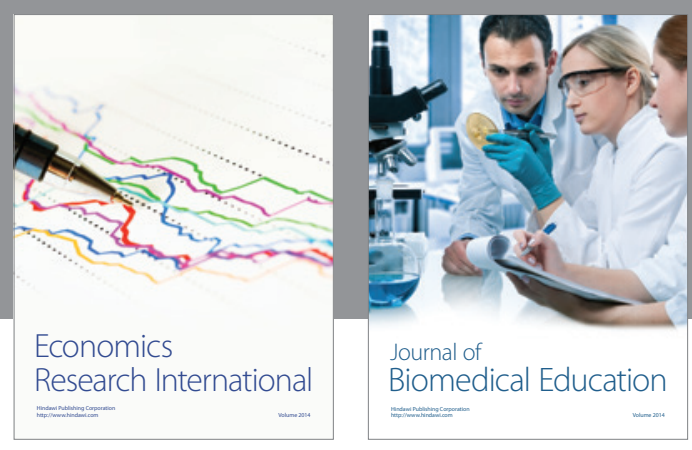

Journal of

Biomedical Education

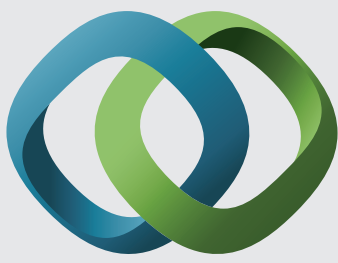

\section{Hindawi}

Submit your manuscripts at

http://www.hindawi.com
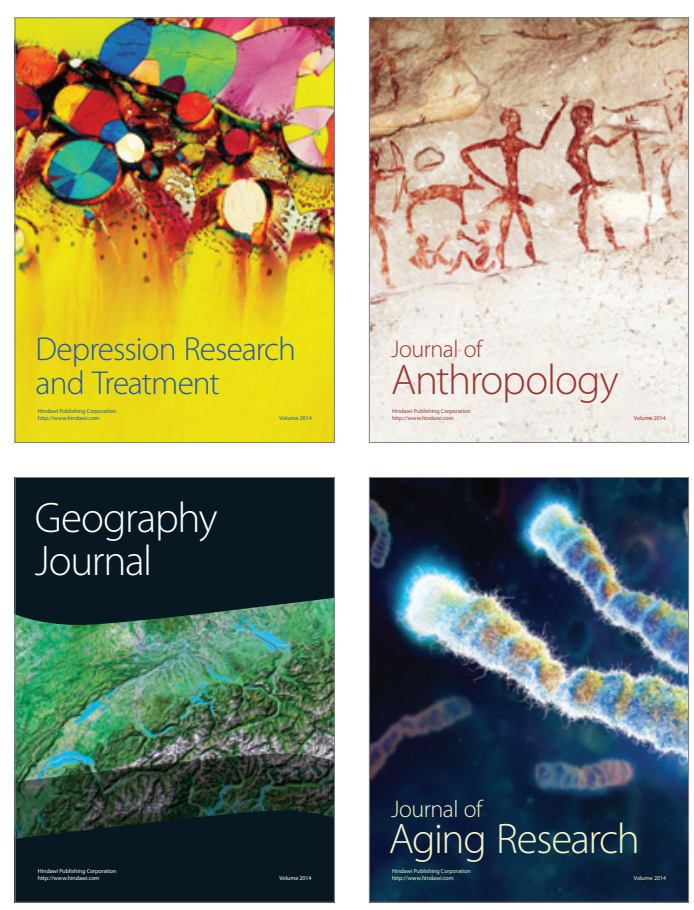

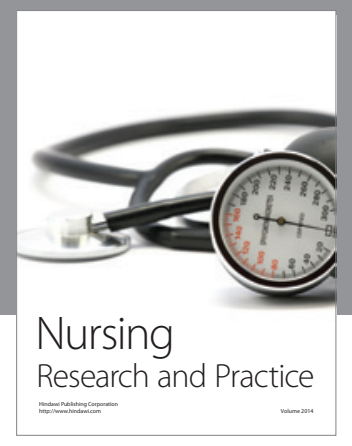

Nursing

Research and Practice

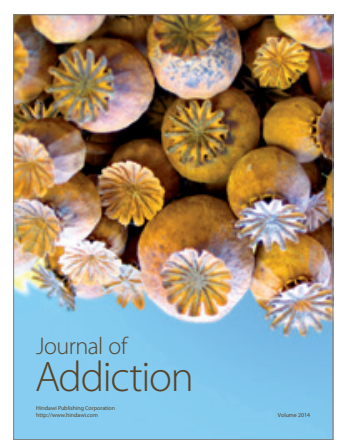

Child Development

Research

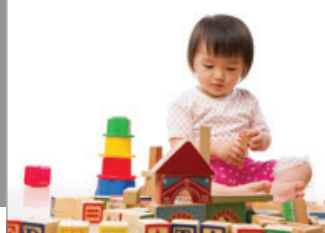

迥
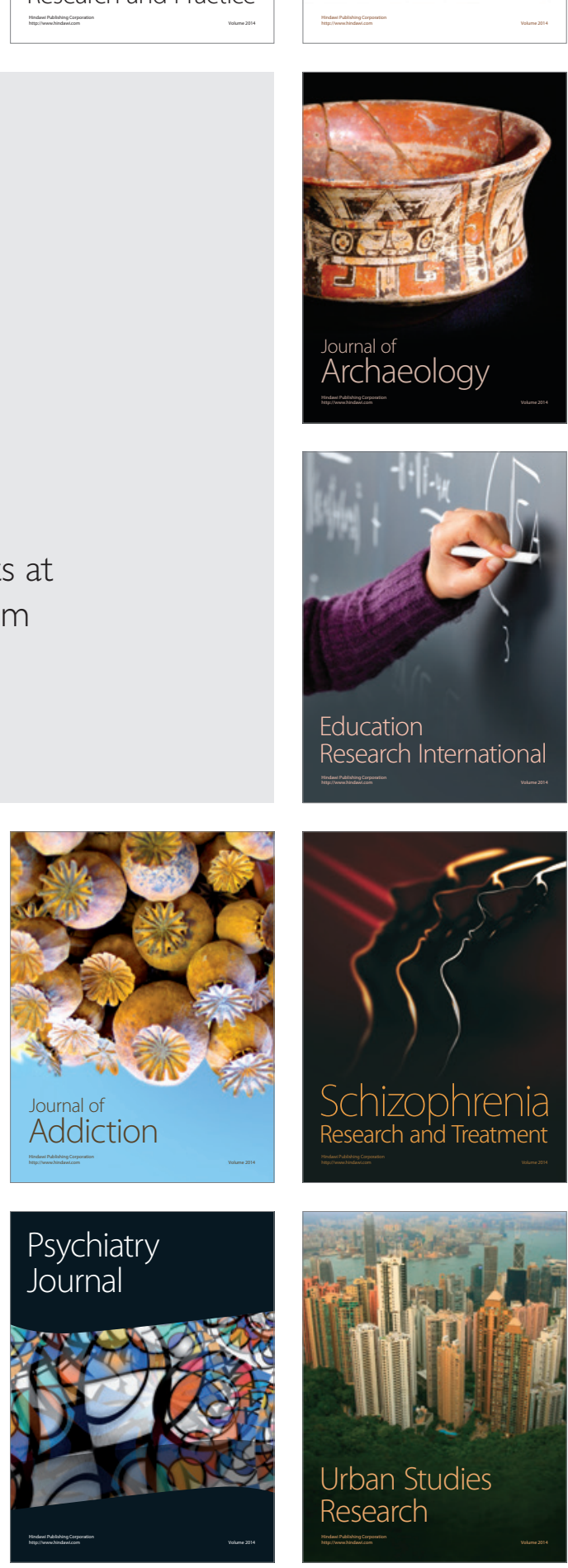